\title{
LA POLÍTICA EXTERIOR DE ESPAÑA HACIA ASIA CENTRAL (2000-2011)
}

\author{
Antonio Alonso ${ }^{1}$ \\ UNISCI/ Universidad San Pablo CEU
}

\begin{abstract}
Resumen:
Aunque las relaciones de España con los actuales países de Asia Central se remontan a varios siglos atrás, fue la desaparición de la Unión Soviética la que abrió una ventana de oportunidades para profundizar en dichas relaciones. España tuvo que confeccionar una Política Exterior orientada hacia estos países, aunque se centró, casi exclusivamente, en su relación con los dos más grandes: Kazajstán y Uzbekistán. Los sucesivos Gobiernos han ampliado y profundizado la cooperación con aquellos actores, sobre todo en materia de seguridad y energía. No obstante, la presencia española en la zona es muy tímida y escasa, a pesar de la buena relación existente entre el Rey D. Juan Carlos y los respectivos Presidentes de las repúblicas centroasiáticas.
\end{abstract}

Palabras clave: Política Exterior Española, Asia Central, Juan Carlos I, Aznar, Zapatero, Nazarbayev, Karimov.

Title in English: "Spain's Foreign Policy towards Central Asia (2000-2011)".

\begin{abstract}
:
Although Spanish relationship with Central Asian countries started some centuries ago, the collapse of the Soviet Union a window of opportunities to deepen such relations. Spain developed a Foreign Policy oriented towards these countries, albeit it focused on the two biggest ones (Kazakhstan and Uzbekistan) almost exclusively. The Spanish Governments have enlarged and deepened the cooperation with those actors, among all in security and energy issues. Nevertheless, the Spanish presence in the area is very tiny and limited, in spite of the good relationship between the King Juan Carlos I and the respective Presidents of the Central Asian Republics.
\end{abstract}

Keywords: Spanish Foreign Policy, Central Asia; Juan Carlos I, Aznar, Zapatero, Nazarbayev, Karimov.

Copyright (C) UNISCI, 2011.

Las opiniones expresadas en estos artículos son propias de sus autores, y no reflejan necesariamente la opinión de UNISCI. The views expressed in these articles are those of the authors, and do not necessarily reflect the views of UNISCI.

\footnotetext{
${ }^{1}$ Antonio Alonso Marcos es profesor del Instituto de Humanidades "Ángel Ayala", Universidad CEU-San Pablo, e investigador de UNISCI.

Dirección: Instituto de Humanidades "Ángel Ayala", Universidad CEU-San Pablo, Paseo Juan XXIII, 8, 28040 Madrid, España.E-mail: aalonso@ceu.es.

http://dx.doi.org/10.5209/rev_UNIS.2011.v27.38148
} 


\section{Introducción}

Las relaciones diplomáticas entre España y Asia Central ${ }^{2}$ se remontan al s. XV cuando Enrique III de Castilla, llamado el Doliente, envió la primera misión diplomática al Gran Tamerlán, poniendo al frente de la misma a un hombre de su confianza: Ruy González de Clavijo (muerto el 2 de abril de 1412). Dicha embajada inició su viaje en 1403 y regresó a la Corte en 1406. El objetivo de dicha embajada era muy sencillo: congraciarse con el emperador mongol que había vencido a Bayaceto I, poniendo así freno al expansionismo turco, en la batalla de Angora (actual Ankara). Sin embargo, la gran distancia que nos separa (alrededor de $6.000 \mathrm{Km}$ ) y una serie de acontecimientos históricos como son la empresa de la Reconquista y del descubrimiento de América, por el lado español, y el ser tierra de disputa entre distintos imperios expansionistas, por parte centroasiática, hicieron que dichas relaciones se vieran interrumpidas hasta que tras el desmoronamiento en 1991 de la Unión de Repúblicas Socialistas Soviéticas surgieron las nuevas republicas independientes de Asia Central.

La Política Exterior, como cualquier política pública, es el reflejo de un programa de gobierno y debe pasar por determinadas fases (planificación, ejecución y evaluación) y, por lo tanto, nuestra presencia allí no es mera casualidad sino que hay detrás toda una intención de emprender dicha acción. Dicho de otro modo, llegó un momento (a finales del siglo XX) en que el Gobierno se convenció de que España debía extender y profundizar sus relaciones con las cinco nuevas republicas centroasiáticas, y se preguntó qué intereses debíamos proteger allí, qué queríamos hacer, qué podíamos hacer, y cuánto dinero de los Presupuestos Generales del Estado estábamos dispuestos a gastar para poder llevarlo a cabo.

Si en los siglos pasados la distancia geográfica ${ }^{3}$ podía ser una excusa, hoy ya no puede serlo tanto ya que los avances técnicos nos permiten surcar los aires a grandes velocidades y establecer puentes aéreos que unan ambos extremos, como ya sucede con el de MadridTaskent de unas 10 horas de duración. Por tanto, esto no puede explicar nuestra ausencia allí. Tampoco puede aducirse que Asia Central es un coto privado de la Federación Rusa, ya que esto es cierto solo en parte tal como lo demuestra la acción de otras potencias, entre ellas

\footnotetext{
${ }^{2}$ La definición más extendida y aceptada del concepto geográfico "Asia Central” incluye a cinco países (Kazajistán, Kirguistán, Tayikistán, Turkmenistán y Uzbekistán). No obstante, desde diversos ámbitos se promueve el uso de conceptos geográficos que excluyen a Kazajistán o que incluyen a Azerbaiyán, a Afganistán, a Mongolia, o a la República Autónoma China de Xinjiang. Ver Sharshenova, Aijan: "Political construction of geography: the US and Russian concepts of Central Asia", POLIS Journal, vol. 2 (Invierno de 2009), en http://www.polis.leeds.ac.uk. Ver también Cowan, P.J.: "Geographic usage of the terms Middle Asia and Central Asia”, Journal of Arid Environments, no. 69 (2007), pp. 359-363. Para el concepto que englobaría Afganistán ver Starr, S. Frederick: “A 'Greater Central Asia Partnership' for Afghanistan and Its Neighbors”, Silk Road Paper (Marzo de 2005), en http://www.silkroadstudies.org.

3 "Señor Presidente, sabemos que Kazajstán es un país de inmensas posibilidades. [...] La distancia geográfica que nos separa no ha de ser un obstáculo, sino un estímulo, para que nos esforcemos en establecer mecanismos de cooperación e intercambio entre nuestras instituciones, nuestras empresas y nuestras gentes". Ver Palabras de Su Majestad el Rey al Presidente de la República de Kazajstán Nursultán Nazarbaiev y al Pueblo Kazako, Madrid, 23 de marzo de 1994.
} 
China o EE.UU., o incluso países de la UE como Alemania ${ }^{4}$, Francia, Reino Unido o incluso Holanda 5 .

Los sucesivos Gobiernos de Felipe González establecieron relaciones diplomáticas con los nuevos países en $1992^{6}$ y pusieron en marcha la cooperación con ellos, de manera más especial, aunque aún tímidamente, con los de mayor envergadura, Kazajstán y Uzbekistán. Los Gobiernos de Aznar dieron un fuerte impulso a estas relaciones, especialmente a raíz de las actividades de la operación "Libertad Duradera" de lucha contra el terror en Afganistán y la posterior reconstrucción del país. Los Gobiernos de Zapatero han consolidado nuestra presencia, aún excesivamente tímida, en toda la región. Dado que el objetivo de esta contribución es mostrar la evolución en los últimos diez años, haremos un repaso somero de lo acontecido antes del año 2000 para centrarnos a continuación en la última legislatura de Aznar y en las dos de Zapatero, ver qué ha sucedido, hacer una evaluación de dichos periodos y proponer una serie de escenarios futuros.

\section{Breve recorrido histórico (1991-2011)}

\subsection{Los primeros años de independencia}

El acceso a la independencia de estas cinco republicas se produjo tras la desaparición de la Unión Soviética en 1991, aunque ya en 1989 se había producido una serie de acontecimientos políticos dentro de la propia URSS que habían profundizado en la descentralización de la Unión trasladando mayor poder a las Republicas Socialistas Soviéticas que la formaban.

Como es de imaginar, el camino de estos países por las desconocidas tierras de la independencia no fue nada fácil, ni en política interior (diferencias étnicas, mantenimiento del orden público, inexistencia de una sociedad civil desarrollada, falta de procedimientos democráticos, por no hablar de la guerra civil tayika), ni en política exterior (establecimiento de nuevas directrices) ${ }^{7}$, ni en lo económico (paso de un sistema comunista en el que el Estado provee absolutamente de todo a la ciudadanía a un sistema de mercado en el que se le deja desprovista, ausencia de una clase media que pague impuestos, entre otros).

Cada una de las cinco republicas recorrió la susodicha senda de la independencia de una manera diferente pudiéndola, grosso modo, describir como sigue:

Kazajstán, gracias a su gran extensión geográfica y su inmenso potencial económico (principalmente gas, petróleo, uranio y aluminio) pudo entrar en la carrera por hacerse con el

\footnotetext{
${ }^{4}$ De hecho Alemania es el lugar elegido por las élites de Asia Central para acudir a su sistema de salud, en concreto por sus tratamientos anti cáncer, como sucedió con el ministro uzbeko de Interior, Zokirjon Almatov, poco después de la masacre de Andiján (Ver Bensmann, Marcus: "Andijan, Germany and Europe", Open Democracy (13 de Mayo de 2008), en http://www.opendemocracy.net, o con el presidente Nazarbayev (Ver Kramer, Andrew E.: "Kazakh Chief Is Said to Be in Germany After Surgery", The New York Times, 20 de Julio de 2011, en http://www.nytimes.com/2011/07/21/world/asia/21kazakhstan.html.

${ }^{5} \mathrm{Si}$ hace 10 años la opción preferencial para las élites era enviar a sus hijos a estudiar a Rusia, hoy han diversificado su elección y les envían a EE.UU., China, India, Alemania o Reino Unido.

${ }^{6} 1992$ fue un año de especial importancia para España, pues celebró tres acontecimientos que centraron la atención internacional: el V Centenario del Descubrimiento de América, las Olimpiadas en Barcelona y la Exposición Universal en Sevilla. Esto hizo que el Gobierno español se volcara en su agenda internacional.

${ }^{7}$ Ver el trabajo del profesor uzbeko Tolipov, Farkhod: "The Foreign Policy Orientations of Central Asian States: Positive and Negative Diversification", en Iwashita, Akihiro (ed.) (2007): "Eager Eyes Fixed on Eurasia: Russia and Its Neighbors in Crisis", Slavic Eurasian Studies, n 16-1, Sapporo, Hokkaido University.
} 
liderazgo regional. Es, sin duda, el país de la zona que mejor ha sabido manejar su nueva situación, tanto desde el punto de vista económico como político, ya que la redistribución de la riqueza ha alcanzado cotas más altas que en otros países vecinos donde los negocios más suculentos están concentrados en las manos de unos pocos, cosa que se puede comprobar nada mas echar una ojeada a las calles de sus ciudades. Dicha redistribución ha permitido crear una clase media que participa cada vez más en los asuntos políticos, aunque de forma moderada ya que el liderazgo del Presidente Nursultán Nazarbayev es ampliamente aceptado por la población $^{8}$.

Kirguistán es un país pequeño, fragmentado étnicamente en dos (un sur netamente uzbeko, un norte kirguís) y dividido en clanes fuertemente integrados ${ }^{9}$. Emprendió una serie de reformas políticas y económicas que les exigían desde las instituciones financieras internacionales, lo que le valió en los años 90 el apelativo de "isla de la democracia". Sin embargo, los intentos del dirigente kirguís por aferrase al poder se encontraron con la oposición de una parte de la población que organizó unas protestas callejeras que le llevaron al exilio en marzo de 2005. La misma suerte corrió en 2010 su sucesor, Bakiyev, quien habiendo hecho promesas de cambio continuo la línea nepotista y de culto al líder del primer presidente, Akayev. La nueva línea impuesta por la presidenta Reza Otonbayeva parece menos personalista y, de hecho, celebró el mismo 2010 un referéndum para que se aprobara una reforma constitucional por la que se le otorgaban más poderes al Parlamento.

Tayikistán se vio sumida en una guerra civil entre 1992 y 1997. Es un país, por lo tanto, que partió con una desventaja añadida de casi diez años respecto al resto de sus compañeros regionales. Sus niveles de pobreza y sus tasas de analfabetismo, junto con el hecho de ser fronterizo con el turbulento Afganistán y muy próximo al no menos preocupante Pakistán, hacen de él uno de los países menos seguros del mundo, cosa que se refleja en la escasa inversión extranjera que se localiza allí.

Turkmenistán es, junto a Kirguistán, el único país que ha cambiado de líder desde 1991. Mientras en Kirguistán dos revueltas populares acabaron con sendos gobernantes, en Turkmenistán hubo que esperar al repentino fallecimiento en diciembre de 2006 del Turkmenbashi (o padre de los turkmenos), el Presidente Saparmurat Niyazov. A lo largo de su mandato, dio muestras de excentricidad suma ${ }^{10}$ que llevaron al país a aislarse prácticamente del resto del mundo. A este le sucedió su hijo no reconocido Gurbanguli Berdimujamedov, quien se hizo con las riendas del poder nada más fallecer su padre y luego se "sometió" a consulta popular que, obviamente, gano por amplia mayoría. Mientras el padre se dedico a dejar sumido al país en la pobreza, la ignorancia y el aislacionismo más absoluto, el hijo está dando pasos para integrar el país a su entorno regional.

Por último, Uzbekistán es el otro país que juega sus bazas para ser líder regional. El Presidente Islam Karimov tuvo que hacer frente a una situación de miseria extendida entre la nación más populosa de Asia Central. La tarea de mantener el orden en semejante crisol de

\footnotetext{
${ }^{8}$ Esto no solo lo confirman las elecciones sucesivas sino estudios sobre el terreno como la encuesta "Kazakhstan after elections" realizada por el Institute of Political Solutions (IPS). Ver http://en.tengrinews.kz .

${ }^{9}$ La tensión étnica explotó en 1990, antes de la caída de la URSS, y luego se reprodujo en varias ocasiones. Ver Choudhury, Bipasha; Denham, Tara; Kumser, Aysen y Romanelli Anthony: "Kyrgyzstan: A Risk Assessment Brief", CIFP and NPSIA, 8 de Octubre de 2008, en http://www.oecd.org.

${ }^{10}$ Publicó una obra, el Rukhnama, una mezcla de Corán y otras enseñanzas populares turkmenas con su propio pensamiento, que hizo de enseñanza obligatoria en las escuelas. Se hizo nombrar varias veces Turkmenbashi. Cambió el nombre de las ciudades en las que había nacido él o alguno de sus familiares. Fundó ciudades con su nombre. Cambió los meses del calendario, dándoles nombres relacionados con su historia personal. Sembró el país de retratos suyos y estatuas doradas que le representaban a él mismo.
} 
minorías fronterizas con el Islam más radical no le dejó muchas opciones y dotó al país de uno de los cuerpos de seguridad más numerosos del mundo (cerca de un millón de policías para unos dieciséis millones de habitantes). Aun así, en estos 20 años de independencia, el país ha logrado mejorar considerablemente su nivel de vida, gracias en parte a la inversión extranjera.

Tras la desaparición traumática de la Unión Soviética estos países buscaron otros apoyos que suplieran los de la Madre Rusia, mirando así hacia China, Turquía, Japón, EE.UU. o la propia Unión Europea. Los atentados del 11-S y la campaña de Afganistán (2001) fue la ocasión para que estos países se orientaran hacia Occidente, buscando su ayuda económica, inversiones extranjeras. Pero pronto se levantaron suspicacias en China y Rusia por dos motivos: por tener en sus respectivos patios traseros a la gran superpotencia (EE.UU) y porque la invasión de Irak (2003) supuso una falta de limites patente y una impunidad prácticamente total en la acción estadounidense fuera de sus fronteras. Desde ese momento, ambas potencias presionaron a sus socios centroasiáticos para que despidieran al aliado occidental, presiones que surtieron efecto en 2005 tras los episodios de la revolución de los tulipanes en Kirguistán (que fue vista como una maniobra de manipulación de la población por parte de asociaciones vinculadas de alguna manera a Occidente) y la masacre de Andiján. Desde ese año, las relaciones se han ido normalizando y se ha ido, siguiendo el modelo kazajo, hacia una diplomacia multivectorial en la que los contactos están diversificados y donde se busca obtener un equilibrio entre los pesos que los distintos actores puedan tener en la economía de ese país (lo que conlleva, en teoría, una cierta capacidad de influencia política).

No obstante, parece que la tendencia no es, precisamente, favorable a los intereses occidentales, sino para China e India. Rusia seguirá manteniendo una buena posición, cosa que no le sucederá a EE.UU. Y si este quedara, muy probablemente, relegado a un segundo plano, iqué decir de los países miembros de la UE o de la Unión como tal! Sin lugar a dudas, si hasta ahora no ha jugado un papel importante, difícilmente lo hará a partir de ahora que cuenta con competidores más atractivos para los centroasiáticos, no sólo por cercanía geográfica, sino también por afinidad cultural y de mentalidad, además del pragmatismo del respeto al "sacrosanto" principio de las relaciones internacionales de no injerencia en asuntos internos de otros países.

Este repaso quedaría incompleto sin hablar del papel de las organizaciones internacionales, actores también de pleno derecho del sistema internacional. En cada una de estas organizaciones sus respectivos "capitanes" juegan bien sus cartas y tratan de influenciar en el resto de países para hacer que se comporten de una determinada manera. Las más activas e influyentes en esta zona son la Organización de Cooperación de Shanghái (capitaneada por China) y la Comunidad de Estados Independientes (dirigida por Rusia). También nos encontramos con la OSCE, que juega un papel importante en el diálogo político entre Oriente y Occidente, pero de escaso peso especifico.

Los países de Asia Central entraron a formar parte de la OSCE en 1991, nada más acceder a la independencia, tal y como hicieron todos los Estados resultantes de la desmembración de la URSS (que era también miembro, más aún, miembro fundador). Entre 1994 y 1995 cada una de las repúblicas formaliza su entrada en la organización, que entonces era sólo "conferencia" (CSCE). La organización estableció en cada uno de los países centroasiáticos una misión, de manera que la OSCE estuvo siguiendo de cerca todo el proceso de transición del modelo soviético a lo que son actualmente. En este punto cabe destacar la especial contribución de Kazajstán a la OSCE al lograr reunir en Astaná en diciembre de 2010 
una Cumbre de Jefes de Estado y de Gobierno ${ }^{11}$, el órgano ejecutivo más importante de la organización, que llevaba sin reunirse desde la cumbre de Estambul en 1999. Por cierto, Kazajstán ostentaba la presidencia rotatoria de la organización gracias al impulso diplomático del Gobierno de Zapatero, y de su ministro Moratinos, quien se esforzó para que recayera en Kazajstán dicha presidencia durante su mandato ${ }^{12}$.

\subsection{La situación actual en las republicas centroasiáticas}

Después de 20 años de independencia, cada uno de estos cinco países han llegado a una situación muy distinta en todos los campos (político, económico, social o educativo); tanto es así que las diferencias entre un país y otro se han exacerbado, de manera que casi no podemos hablar de Asia Central como realidad homogénea sino más bien de una región plagada de contrastes abismales, lo que puede suponer una fuente potencial de conflicto. De hecho, las diferencias entre Kazajstán (el país más desarrollado y avanzado en todos los aspectos) y Tayikistán (el último de la región) son tan amplias que nadie se atrevería a afirmar que tan solo hace 20 años pertenecían a un mismo ente político (la URSS) ${ }^{13}$.

Estas diferencias se pueden ver en cualquier indicador que elijamos ${ }^{14}$. Aquí, los números hablan por sí mismos, especialmente cuando lo comparamos entre ellos, con los vecinos y con la UE. Sin embargo, los datos empíricos, objetivos (como son los indicadores ofrecidos por el Banco Mundial) son más fiables que aquellos otros datos que introducen una valoración subjetiva y que están sujetos, por tanto, a la opinión de quien interpreta otros datos objetivos. Es el caso de los indicadores de Freedom House, que afirmó en 2009 que Kirguistán sería un país estable y, por tanto, se mostró incapaz de predecir (anticipar) las revueltas sangrientas de 2010.

Los informes o análisis realizados por expertos que están sobre el terreno o que conocen muy bien la zona ayudan a hacerse una idea acerca de la estabilidad de la región ${ }^{15}$. Estos expertos señalan varios peligros que amenazan a Asia Central en su conjunto, entre ellos el islamismo radical (que puede derivar en actos de terrorismo) ${ }^{16}$, los movimientos separatistas dentro de naciones poco integradas socialmente o con graves deficiencias económicas (especialmente en Kirguistán y Tayikistán), los tráficos ilícitos (actividad en torno a la cual se genera una gran cantidad de actividades delictivas que atentan contra la seguridad y la estabilidad regional como son la trata de blancas, el tráfico de armas, narcotráfico, incremento de la corrupción, aumento del número de adictos a las drogas, mayores tasas de analfabetización, deterioro del tejido económico de una región,...), la gestión del agua y la energía (los problemas medioambientales pueden conducir a tensiones entre los países de la zona, sea por sequías, sea por inundaciones,...).

\footnotetext{
11 Ver Ruiz González, Francisco J.: "La arquitectura de seguridad europea: evolución, situación actual y perspectivas", en Real Instituto Elcano, Panorama estratégico 2011-2012, p. 97.

${ }_{12}$ Sobre las duras negociaciones para que la diplomacia española consiguiera este objetivo, ver "Spain and Kazakhstan in the chair", EUCAM Watch, n.7, diciembre de 2009, en http://www.eucentralasia.eu.

${ }^{13}$ El índice IDH de la UNDP muestra gráficamente cómo Kazajstán se asemeja en sus resultados a Rusia y a Europa y se distancia cada vez más de sus vecinos centroasiáticos.

${ }^{14}$ Las principales organizaciones que nos ofrecen estos indicadores son UN, UNDP, World Bank, y Freedom House.

${ }^{15}$ Ver Stavridis, Stelios y De Prado, César (coord.) (2010): Panorámicas de actores y factores en Asia Central. Zaragoza, Prensas Universitarias de Zaragoza. Ver también Emerson, Michael; Boonstra, Jos; Hasanova, Nafisa; Laruelle, Marlene y Peyrouse, Sebastien (2010): Into EurAsia - Monitoring the EU's Central Asia Strategy. Madrid, FRIDE.

${ }^{16}$ Ver Olimova, Saodat y Tolipov, Farkhod: "Islamic revival in Central Asia: The cases of Uzbekistan and Tajikistan”, Documentos CIDOB Asia, no. 26 (Marzo de 2011), en http://www.cidob.org.
} 
Otro problema que coinciden en señalar los observadores internacionales, es el lento proceso de transición a la democracia liberal de estos países ${ }^{17}$, llegando incluso algunos de ellos a afirmar que no existe tal proceso de transición sino que dichos regímenes se han estancado en una forma de falsa democracia ("fake democracy") o que son directamente autoritarios ${ }^{18}$. Especialmente, echan en falta un mayor protagonismo de la sociedad civil, una mayor representatividad de las minorías y un ejercicio más pleno de las libertades públicas (manifestación, asociación, organización, expresión,...). Además, denuncian el carácter personalista de estos sistemas políticos y el excesivo peso del Jefe del Estado, que anula al propio Jefe de Gobierno y al resto de Ministros. Además, el carácter aparentemente vitalicio de la Presidencia de la República ayuda a confirmar esa denuncia.

\begin{tabular}{|c|c|c|c|c|c|}
\hline & Kazajstán & Kirguistán & Tayikistán & Turkmenistán & Uzbekistán \\
\hline $\mathrm{PIB}^{19}$ & 142.986 .931 .560 & 4.616.156.122 & 5.640 .410 .959 & 21.074 .000 .000 & 38.981 .605 .338 \\
\hline $\mathrm{PIBpc}^{20}$ & 11.927 & 2.332 & 2.065 & 7.627 & 3.084 \\
\hline $\mathrm{IDH}^{21} 2011$ & 0,714 & 0,598 & 0,58 & 0,669 & 0,617 \\
\hline $\begin{array}{l}\text { Posición IDH } \\
2011\end{array}$ & 66 & 109 & 112 & 87 & 102 \\
\hline $\begin{array}{l}\text { Tasa de } \\
\text { alfabetización de } \\
\text { adultos }\end{array}$ & $99,6 \%$ & $99,3 \%$ & $99,7 \%$ & $99,5 \%$ & $96,9 \%$ \\
\hline $\begin{array}{l}\text { Esperanza de } \\
\text { vida }^{22}\end{array}$ & 65 & 67,9 & 66,8 & 64,8 & 67,8 \\
\hline $\begin{array}{l}\text { Derechos } \\
\text { políticos }^{23}\end{array}$ & 6 & 5 & 6 & 7 & 7 \\
\hline $\begin{array}{l}\text { Libertades } \\
\text { civiles }\end{array}$ & 5 & 5 & 5 & 7 & 7 \\
\hline $\begin{array}{l}\text { Voz y } \\
\text { responsabilidad }^{24}\end{array}$ & $-1,04$ & $-0,96$ & $-1,33$ & $-2,06$ & $-1,93$ \\
\hline $\begin{array}{l}\text { Estabilidad } \\
\text { política y } \\
\text { ausencia de } \\
\text { violencia }\end{array}$ & 0,642 & $-0,54$ & -1 & 0,181 & $-0,91$ \\
\hline $\begin{array}{l}\text { Eficacia del } \\
\text { Gobierno }\end{array}$ & $-0,19$ & $-0,98$ & $-1,11$ & $-1,34$ & $-0,72$ \\
\hline $\begin{array}{l}\text { Calidad } \\
\text { regulatoria }\end{array}$ & $-0,37$ & $-0,36$ & $-1,08$ & $-2,07$ & $-1,55$ \\
\hline $\begin{array}{l}\text { Estado de } \\
\text { Derecho }\end{array}$ & $-0,56$ & $-1,29$ & $-1,22$ & $-1,37$ & $-1,22$ \\
\hline $\begin{array}{l}\text { Control de la } \\
\text { corrupción }\end{array}$ & $-0,91$ & $-1,22$ & $-1,11$ & $-1,43$ & $-1,26$ \\
\hline
\end{tabular}

\footnotetext{
${ }^{17}$ Ver Polyanicheva, Irina (ed.) (2009): The Years That Changed Central Asia. Center for Strategic \& Political Studies, Moscú, especialmente las pp. 7ss.

${ }^{18}$ Ver Brill Olcott, Martha: "Eyes on Central Asia: How to Understand the Winners and Losers", en Iwashita, Akihiro (ed.) (2007): "Eager Eyes Fixed on Eurasia: Russia and Its Neighbors in Crisis", Slavic Eurasian Studies, no. 16-1, Sapporo, Hokkaido University.

${ }^{19}$ Datos ofrecidos por el Banco Mundial, referidos al año 2010, expresados en dólares americanos (US\$). España, según estos datos, ingresó 1.407.405.298.013 US\$ en 2010. Ver http://data.worldbank.org.
} 
No obstante, una mirada en profundidad a la realidad de estos países nos ofrece una imagen distinta, ya que el desarrollo político, social y económico no es igual en cada uno de estos Estados. Así, el avance económico de Kazajstán, ha hecho del país en estos 20 años un lugar en el que la población en general entiende que tiene una oportunidad para prosperar: hay fácil acceso a la educación, se dan oportunidades de trabajo, se ha creado una amplia clase media que puede disfrutar de un nivel de consumo aceptable, se ofrecen espacios de expresión a las minorías étnicas y religiosas,... El Gobierno español ha declarado en multitud de ocasiones su apoyo a los progresos realizados por Kazajstán, especialmente en el campo económico; y prueba de esa confianza en la economía kazaja es el objetivo de que "Hay que sembrar una mayor presencia de empresas españolas" ${ }^{25}$. No hay que olvidar que el Ministro Moratinos declaró en Kazajstán que Asia Central es un "área prioritaria"26 para España. Baste recordar las palabras de Juan Carlos I:

Seguimos de cerca y valoramos los esfuerzos que, para avanzar y ahondar en el proceso democrático, realiza el gran país amigo que es Kazajstán, situado entre dos continentes. [...] Sabemos que en una nación como Kazajstán, que engloba a más de 130 grupos culturalmente diferentes, el mantenimiento de la armonía social y de la tolerancia interétnica constituye un objetivo fundamental. Queremos expresaros nuestro apoyo a la integridad territorial y la soberanía de Kazajstán, y a toda iniciativa que conduzca a afianzar la cohesión social y el Estado. $^{27}$

El Gobierno español tiene como uno de los objetivos principales fomentar la estabilidad política de la zona para poder desarrollarse económicamente, como afirma Eugenio Salarich:

"Ha llegado el momento de recoger en el ámbito económico lo que se ha sembrado políticamente en los últimos años", resume a Efe José Eugenio Salarich, director general de Relaciones Económicas Internacionales y Asuntos Energéticos en el Ministerio de Asuntos Exteriores desde el pasado mes de agosto. [...] Según el director de Relaciones Económicas

\footnotetext{
${ }^{20}$ Medido en dólares americanos (US\$). Datos del año 2008.

${ }^{21}$ El Índice de Desarrollo Humano es uno de los más completos pues es el resultado de combinar otros tres indicadores: PIBpc, esperanza de vida y tasa de alfabetización. La UNDP lo utiliza para medir el desarrollo real que llega a la gente de un país, a la población general, ya que viene definido como una vida larga y saludable, educación y nivel de vida digno. Los valores van de 1 (posición óptima) a 0 (la pésima). Ver el elocuente gráfico en http://hdr.undp.org.

${ }^{22}$ La esperanza de vida al nacer es un índice muy complejo y se mide en años. Más concretamente, son los años que un recién nacido puede esperar vivir si los patrones de mortalidad por edades imperantes en el momento de su nacimiento siguieran siendo los mismos a lo largo de toda su vida.

${ }^{23}$ Datos ofrecidos por Freedom House. Los "derechos políticos" y "libertades civiles" son índices muy complejos, formados por diversos indicadores y datos que orientan hacia una valoración entre 1 (situación óptima) y 7 (pésima). Según Freedom House, sólo Kirguistán tendría carácter de país "parcialmente libre” y el resto sería "no libre", lo que significaría que los derechos fundamentales son sistemáticamente denegados.

${ }^{24}$ El Banco Mundial utiliza una serie de indicadores para medir la estabilidad política y la gobernanza de un país, a saber: voz y responsabilidad, estabilidad política y ausencia de violencia, eficacia del Gobierno, calidad regulatoria, Estado de Derecho y control de la corrupción. Aquí aparecen los datos correspondientes a 2009. La estimación se presenta en punto desde la situación pésima $(-2,5)$ hasta la óptima $(2,5)$.

${ }^{25}$ Ver "Zapatero viaja hoy a Kazajistán junto a empresarios para impulsar el comercio", ABC.es, 16 de Junio de 2011, en http://www.abc.es/20110616/espana/abci-zapatero-viaje-201106161024.html.

${ }^{26}$ Ver "Moratinos afirma en Kazajistán que Asia Central es 'prioritaria' para España", Elmundo.es, 11 de Abril de 2007, en http://www.elmundo.es/elmundo/2007/04/11/espana/1176292906.html.

${ }^{27}$ Ver Palabras de Su Majestad el rey en el almuerzo ofrecido en honor del Presidente de Kazajstan, Excmo. Sr. Nursultan Nazarbaev, Madrid, 30 de Octubre de 2000, en http://www.casareal.es.
} 
de Exteriores, "el objetivo debe ser "vender" país y aprovechar la buena red de contactos políticos" para que las empresas españolas "sean tratadas favorablemente" en las adjudicaciones. ${ }^{28}$

Además, Kazajstán realiza un gran papel como estabilizador regional al tener una diplomacia multivector y muy activa en el campo de la prevención y resolución de conflictos, como se puede ver en su papel en la OSCE, la OCI, la OCS o la CICA. Así lo reconoce el Secretario General de la OSCE:

En 2010, Kazajstán se convirtió en el primer Estado de Asia Central y la primera antigua República Soviética con mayoría de población musulmana que presidía la OSCE. Este impresionante éxito, alcanzado bajo la Presidencia de Nursultan Nazarbayev, ha merecido el objetivo reconocimiento de la comunidad internacional y es una prueba de la importante contribución de Kazajstán a la seguridad regional y global. ${ }^{29}$

Kirguistán, debido a su inestabilidad política, derivada de su falta de integración étnica y social, es un foco de problemas para toda la región ${ }^{30}$. Los enfrentamientos entre clanes en su lucha por el poder se han disfrazado de intenciones democráticas, pero dicho disfraz sólo puede durar unos años (como en el caso de Bakiyev). Además, el problema de los uzbekos del sur del país amenaza con romper el país en dos, pasando, obviamente, por una guerra civil con posible intervención uzbeka. ${ }^{31}$

Tayikistán, el país menos próspero y más empobrecido de los cinco centroasiáticos, es la fuente de mayor preocupación debido, principalmente, a la amenaza de extremismo islamista que puede ser caldo de cultivo para facciones guerrilleras que protesten de manera violenta contra la situación económica y social del país, además de ofrecer un paso seguro de otros grupos terroristas desde Pakistán-Afganistán hacia otros países de Asia Central.

Turkmenistán es, sobre todo para Occidente, una gran incógnita ya que aún se desconoce cómo el sucesor de Niyazov va a gestionar la enorme balsa de gas y petróleo que heredó de su antecesor. Más interesados en sus hidrocarburos que en la evolución política y social del país, los gobiernos occidentales guardan un sospechoso silencio con respecto a esta nación, una de las más cerradas al exterior de todo el mundo. Un dato que sí ha logrado traspasar sus fronteras es que no ha habido una mínima redistribución de la riqueza entre la población general, aprovechando sus inmensos recursos naturales.

\footnotetext{
28 "Trinidad Jiménez practicará la "diplomacia económica"”, eleconomista.es, 9 de enero de 2011, en http://www.eleconomista.es/espana/noticias/2727764/01/11/Trinidad-Jimenez-practicara-la-diplomaciaeconomica.html.

${ }^{29}$ Informe Anual sobre las Actividades de la OSCE en 2010, p. 13.

${ }^{30}$ Ver los informes del kirguís Institute for Public Policy en http://www.ipp.kg, entre ellos Ukushov, Marat: "Kyrgyzstan follows its Constitution?".

${ }^{31}$ Tras las tempestades políticas de mayo y junio llegó en julio y agosto la calma a Kirguistán y se pudo crear una comisión de investigación, la KIC (Kyrgyzstan Inquiry Comission) que elaboró un Informe Final que esclareció lo acontecido en el país centroasiático desde comienzos de 2010. Ver el Report of the Independent International Commission of Inquiry into the Events in Southern Kyrgyzstan In June 2010, en http://www.kic.org, Ver un resumen comentado por Riedel Christya: "International Commission On The Kyrgyz Violence in 2010”, Foreign Policy Association, 3 de Mayo de 2011, en http://foreignpolicyblogs.com.
} 
Por último, el caso de Uzbekistán es más preocupante aún, pues es uno de los dos países que luchan por ejercer el liderazgo regional y centra la atención de todas las potencias (Rusia, China, EE.UU., la UE). También es rica en hidrocarburos, pero dicha riqueza no ha llegado a muchas manos, como puede comprobarse en la diferencia de renta per capita que hay entre estos países. Aunque el Gobierno uzbeko desea dar muestras al exterior de que su país está haciendo avances en materia de derechos civiles y políticos, que está mejorando la educación, etc la realidad es que la oposición (pacífica) al régimen debe pagar un alto precio por existir y está estrechamente vigilada y perseguida. Este hecho es, en realidad, más peligroso para la estabilidad del país que la propia amenaza islamista (que es real, aunque muchos autores digan que no lo es;). El terrorismo ya ha hecho acto de presencia en este país y no es de extrañar que en el próximo año se vivan situaciones de violencia extrema debido a este fenómeno. Buen resumen de todo esto son las palabras de S.M. Juan Carlos I:

La Unión Europea y España han venido apoyando los esfuerzos de modernización de Uzbekistán a través del Acuerdo de Cooperación y Colaboración, en vigor desde 1999. Para que esta cooperación resulte plenamente fructífera es preciso avanzar en el proceso de reformas políticas y económicas que permita consolidar una economía de mercado, atraer inversiones extranjeras y aumentar y diversificar los intercambios comerciales. Las reformas estructurales y la liberalización económica son requisitos esenciales e indispensables para impulsar el desarrollo, la prosperidad y la plena inserción de Uzbekistán en la economía internacional. ${ }^{32}$

En conclusión, tenemos un panorama regional bastante preocupante por los factores de inestabilidad que la amenazan, incluso a medio plazo, aunque debido a los efectos de la crisis económica dicho plazo podría verse reducido y sufrir episodios de violencia, como los sufridos en 2010 en Kirguistán ${ }^{33}$.

En el lado positivo, tenemos que hay países, como Kazajstán, que están trabajando duro para progresar en todos los campos (político, económico, social) y hacer de la región (no sólo su propio país) un área más segura y estable con iniciativas internacionales como las citadas anteriormente, como lo expresaba ya S.M. Juan Carlos I en 1994: "La adhesión de Kazajstán al Tratado de no proliferación en calidad de país no poseedor de armas nucleares, es una importante y alentadora contribución a la paz, y ha hecho a vuestro país acreedor a la mayor consideración internacional". 34

El Informe Anual sobre las Actividades de la OSCE en 2010, realizado por el Secretario General de la OSCE, Marc Perrin de Brichambaut, expresa el lado positivo y negativo de este análisis:

Asia Central también ocupó el centro de atención en 2010 por otros motivos, cuando Kirguistán tuvo que hacer frente a varios problemas en abril y junio. La Presidencia [kazaja] reaccionó ante la crisis asumiendo la dirección de la respuesta coordinada de la OSCE, en colaboración con las Naciones Unidas y la Unión Europea. La Secretaría de la OSCE, el Centro en Bishkek y las Instituciones [...] mancomunaron esfuerzos que contribuyeron a

\footnotetext{
${ }^{32}$ Ver Palabras de S.M. el Rey en la cena de gala en honor del Presidente de la República de Uzbekistán. Palacio Real de Madrid, 27 de Enero de 2003, en http://www.casareal.es.

${ }^{33}$ Ver Kassenova, Nargis: "The impact of the global economic crisis on Central Asia and its implications for the EU engagement", EUCAM Working Paper, n 5, en http://www.eucentralasia.eu.

${ }^{34}$ Ver Palabras de Su Majestad el Rey al Presidente de la República de Kazajstán Nursultán Nazarbaiev y al Pueblo Kazako. Madrid, 23 de marzo de 1994, en http://www.casareal.es.
} 
estabilizar la situación y devolverla a la senda constitucional. Los Estados participantes de la OSCE siguieron brindando asistencia a Kirguistán, a petición de ese país, y a final del año ya habían puesto en marcha la Iniciativa en favor de una Seguridad Comunitaria, para brindar apoyo y asesoramiento a las fuerzas policiales del país. ${ }^{35}$

\subsection{Sus relaciones con la $\mathrm{UE}$}

Mención aparte merece la relación de los países de Asia Central con la UE por varios motivos $^{36}$. En primer lugar porque las primeras relaciones de España con algunos de estos países (en concreto con Uzbekistán) se hicieron, precisamente, a través de las Comunidades Europeas. En segundo lugar, porque España está inserta en la UE y con ella deberá coordinar en el futuro su acción exterior, también en el caso de Asia Central, para el que la Comisión aprobó una Estrategia ${ }^{37}$. Y en tercer lugar, porque España llega tarde y mal, en comparación con otros países miembros de la UE que, en lugar de cooperar, compiten (ferozmente) con ella (y sus empresas). Esta situación en el exterior tiene su origen y sus consecuencias en el seno de los órganos de decisión de la Unión.

Desde diciembre de 1989, como recordó el diputado Estrella Pedrosa, se iniciaron una serie de acuerdos entre las Comunidades Europeas y la URSS ${ }^{38}$. Así, encontramos que el 23 de enero de 1995 se firma en Bruselas un "Acuerdo de colaboración y cooperación entre las Comunidades Europeas, y sus estados miembros, por una parte, y la república de Kazajstán, por otra". Ambas partes se mostraban "convencidas de la importancia capital del Estado de Derecho y del respeto de los Derechos Humanos, especialmente los de las minorías, de la creación de un sistema pluripartidista con elecciones libres $\boldsymbol{y}$ democráticas y de una liberalización económica destinada a establecer una economía de mercado" y condicionaban el cumplimiento de dicho acuerdo a "la continuación y cumplimiento de las reformas políticas, económicas y legislativas de la República de Kazajstán". Por este Acuerdo, la Europa de los 15 se comprometía, según el art. 1, a:

- ofrecer un marco apropiado para el diálogo político entre las Partes que permita el desarrollo de relaciones políticas;

- fomentar la expansión del comercio y unas relaciones económicas armoniosas entre las Partes para favorecer así el desarrollo económico sostenible de las mismas;

- ofrecer una base para la cooperación económica, social, financiera, científica civil, tecnológica y cultural mutuamente provechosa; - apoyar los esfuerzos de la República de Kazajstán para consolidar su democracia y desarrollar su economía y completar la transición a una economía de mercado.

\footnotetext{
${ }^{35}$ Informe Anual sobre las Actividades de la OSCE en 2010, p. 4.

${ }^{36}$ Sobre la relación con la UE ver Soto, Augusto: “Asia Central en el fluido horizonte geoestratégico de la UE”, Real Instituto Elcano, DT 29/2007 (21 de junio de 2007). Ver también Fernández Sola, Natividad: “Asia Central y el Cáucaso Sur en la estrategia de la UE”, Real Instituto Elcano, DT 21/2009 (28 de abril de 2009).

37 Ver todos los documentos en http://www.eeas.europa.eu. Especialmente, los Strategy Paper 2002-2006 y Strategy Paper 2007-2011.

${ }^{38}$ Ver el Diario de Sesiones del Congreso de los Diputados no 130 (18 de diciembre de 1996), p. 3589.
} 
Los principios generales que guían este Acuerdo, como se afirma en el art. 2, son "el respeto a la democracia, a los principios del Derecho Internacional y a los Derechos Humanos, tal como se definen en particular en el Acta Final de Helsinki y en la Carta de París por una nueva Europa, y también los principios de la economía de mercado". Además, se anima a Kazajstán a seguir cultivando unas relaciones de buena vecindad con los demás países centroasiáticos (art. 3).

El Acuerdo dedica el Título II a explicar el "diálogo político" (especialmente el art. 4) al que antes se hacía referencia (art. 1) y que

- fortalecerá los vínculos de la República. de Kazajstán con la Comunidad y, por ende, con la comunidad de naciones democráticas. La convergencia económica que se logre mediante el presente Acuerdo dará lugar a unas relaciones políticas más intensas;

- conducirá a una mayor convergencia de posiciones en las cuestiones internacionales de interés mutuo, con lo que aumentará la seguridad y la estabilidad.

A estos artículos de índole política, le siguen otros sobre cuestiones económicas (circulación de mercancías, al comercio y a las inversiones, legislación económica y aduanera, cooperación económica, cooperación en ciencia y tecnología, en enseñanza y formación, el turismo, entre otras), especialmente el dedicado a la energía.

El inicio de las relaciones de España con el actual Uzbekistán se remonta al año 1996, cuando las Comunidades Europeas firmaron en Florencia un "Acuerdo de colaboración y cooperación por el que se establece una colaboración entre las Comunidades Europeas y sus Estados miembros, por una parte, y la república de Uzbekistán, por otra", y un "Acta Final" de dicha reunión ${ }^{39}$. En dicho Acuerdo, se aclara, en su art. 53.2, cuáles son los intereses en común; de los nueve que se enumeran, ocho están directamente relacionados con la energía y el otro restante trata sobre la "mejora de la gestión y la reglamentación del sector de la energía que se adapte a una economía de mercado".

Como afirmó Estrella Pedrosa en un debate en la Comisión de Exteriores en el Congreso de los Diputados, se trata de un acuerdo muy amplio, incorporando la denominada "cláusula democrática", que condicionaba la vigencia de dicho acuerdo, y se orientaba a la consecución de la estabilidad de la región:

Se trata de un acuerdo de cooperación no preferencial que tiene como objetivo contribuir, en el caso de este importante país, con un gran futuro, al esfuerzo de reconstrucción económica, al esfuerzo de lanzamiento de su economía, de su industria, a través de un impulso al desarrollo sostenible. ${ }^{40}$

En este debate, el diputado popular Milián Mestre recuerda la importancia geoestratégica de Uzbekistán:

\footnotetext{
${ }^{39}$ Firmados en Florencia el 21 de junio de 1996 y publicado en el BOE n ${ }^{\text {2 }}$ 200, de 21 de agosto de 1999.

${ }^{40}$ Ver el Diario de Sesiones del Congreso de los Diputados no 130 (18 de diciembre de 1996), p. 3589.
} 
En este caso, en naciones como Uzbekistán, con altísimos intereses específicos en el campo de la energía y del petróleo y por su ubicación en el centro asiático, supone, sin duda, un cúmulo de intereses de primer orden, que es lo que contemplan en este caso el acuerdo, los cinco anexos, un protocolo, ocho declaraciones conjuntas y finalmente una declaración singularizada del Gobierno francés. ${ }^{41}$

\subsection{Sus relaciones con España}

En estos 20 años de independencia, los países de Asia Central se han relacionado, en mayor o menor medida, con España, pudiéndose distinguir varias etapas, coincidiendo con los sucesivos Gobiernos españoles.

Una de las principales características de nuestras relaciones con estos países es el papel tan importante que juega Juan Carlos $\mathrm{I}^{42}$ y su estrecha relación personal, consolidada con el paso de los años, con los mandatarios del otro lado del Caspio, especialmente con el presidente Nursultán Nazarbayev (de Kazajstán) y con el presidente Islam Karimov (de Uzbekistán), que son los dos países con los que mantenemos vínculos más estrechos.

Los intereses de España en la región son principalmente económicos, comerciales, energéticos ${ }^{43}$ y de seguridad (especialmente a partir de 2002, por la presencia del Ejército español en Afganistán), mientras que otros intereses ideológicos como la defensa de los Derechos Humanos y el avance democrático pasan a un segundo plano, casi exclusivamente, a los discursos pronunciados por el Jefe del Estado $^{44}$ y a las declaraciones oficiales de la UE ${ }^{45}$. No obstante, los esfuerzos diplomáticos por impulsar la Alianza de Civilizaciones no han estado en un segundo plano sino más bien en primera línea.

\begin{tabular}{|c|c|}
\hline \multicolumn{2}{|c|}{ Convenios firmados por España } \\
\hline \multicolumn{1}{|c|}{ Kazajstán } & \multicolumn{1}{|c|}{ Uzbekistán } \\
\hline $\begin{array}{l}\text { Acuerdo para la promoción y protección } \\
\text { recíproca de inversiones entre el Reino de }\end{array}$ & $\begin{array}{l}\text { Acuerdo de Colaboración y Cooperación por } \\
\text { el que se establece una colaboración entre las } \\
\text { Comunidades Europeas y sus Estados }\end{array}$ \\
\hline
\end{tabular}

\footnotetext{
${ }^{41}$ Ibid.

42 "Spanish King Juan Carlos and Kazakh President Nazarbaev have developed a close friendship (they are said to go hunting together). The last occasion was Nazarbaev's visit to the International Expo in Zaragoza”. Ver "Spain and Kazakhstan in the chair", EUCAM Watch, no. 7 (diciembre de 2009), en http://www.eucentralasia.eu. ${ }^{43}$ Ver Blanc Altemir, Antonio: "La seguridad en el suministro energético, en particular de gas, como prioridad estratégica de la UE: ¿existen alternativas viables que reduzcan la dependencia de Rusia?", Real Instituto Elcano: Panorama estratégico 2011-2012, p. 219.

44 "Señor Presidente: Ninguno ignoramos las dificultades y vicisitudes a que pueden estar sometidas las democracias jóvenes [...] Por ello, seguimos de cerca y valoramos los esfuerzos que, para avanzar y ahondar en el proceso democrático, realiza el gran país amigo que es Kazajstán, situado entre dos continentes [...] Para culminar ese proceso hay que recorrer un largo camino, no exento de dificultades internas y externas. Por eso resulta necesario un esfuerzo constante apoyado en la voluntad política de establecer instituciones democráticas y flexibles". Ver Palabras de Su Majestad el rey en el almuerzo ofrecido en honor del Presidente de Kazajstan, Excmo. Sr. Nursultan Nazarbaev. Madrid, 30 de Octubre de 2000.

${ }^{45}$ En este sentido, ver las declaraciones de la Presidencia en nombre de la UE sobre varios asuntos, tales como los fraudes electorales en Kirguistán o el instigamiento a los opositores en aquel país. Ver Monografía del MAEC sobre Kirguistán (2007), pp. 31-35.
} 


\begin{tabular}{|c|c|}
\hline España y la República de Kazajstán. 1994. & $\begin{array}{l}\text { Miembros, por una parte, y la República de } \\
\text { Uzbekistán por otra. } 1996\end{array}$ \\
\hline $\begin{array}{l}\text { Acuerdo de colaboración y cooperación entre } \\
\text { las Comunidades Europeas y sus Estados } \\
\text { miembros, por una parte, y la República de } \\
\text { Kazajstán, por otra. } 1995 \text {. }\end{array}$ & $\begin{array}{l}\text { Acuerdo para la promoción y protección } \\
\text { recíproca de inversiones entre el Reino de } \\
\text { España y la República de Uzbekistán. } 2003 \text {. }\end{array}$ \\
\hline $\begin{array}{l}\text { Acuerdo sobre cooperación económica e } \\
\text { industrial entre el Reino de España y la } \\
\text { República de Kazajstán. } 1997 \text {. }\end{array}$ & \\
\hline $\begin{array}{l}\text { Convenio de Cooperación Cultural, } \\
\text { Educativa y Científica entre el Reino de } \\
\text { España y la Republica de Kazajstán. } 1998 .\end{array}$ & \\
\hline $\begin{array}{l}\text { Acuerdo entre el Gobierno del Reino de } \\
\text { España y el Gobierno de la República de } \\
\text { Kazajstán sobre transporte internacional de } \\
\text { viajeros y mercancías por carretera. } 2007 \text {. }\end{array}$ & \\
\hline $\begin{array}{l}\text { Acuerdo entre Gobierno del Reino de España } \\
\text { y el Gobierno de la República de Kazajstán } \\
\text { sobre el tránsito de equipos y personal } \\
\text { militares a través del territorio de la } \\
\text { República de Kazajstán con motivo de la } \\
\text { participación del Reino de España en los } \\
\text { esfuerzos internacionales para la } \\
\text { estabilización y reconstrucción de la } \\
\text { República Islámica de Afganistán. 2009. }\end{array}$ & \\
\hline $\begin{array}{l}\text { Convenio entre el Gobierno del Reino de } \\
\text { España y el Gobierno de la República de } \\
\text { Kazajstán para evitar la doble imposición y } \\
\text { prevenir la evasión fiscal en materia de } \\
\text { impuestos sobre la renta y sobre el } \\
\text { patrimonio. 2009. }\end{array}$ & \\
\hline $\begin{array}{l}\text { Acuerdo de Asociación Estratégica entre el } \\
\text { Reino de España y la República de } \\
\text { Kazajstán. 2010. }\end{array}$ & \\
\hline $\begin{array}{l}\text { Acuerdo entre el Gobierno del Reino de } \\
\text { España y el Gobierno de la República de } \\
\text { Kazajstán sobre supresión recíproca de } \\
\text { visados en pasaportes diplomáticos. } 2010 \text {. }\end{array}$ & \\
\hline
\end{tabular}

Analizando los acuerdos firmados, se puede ver cuáles son los objetivos del Gobierno español en Asia Central, a saber: mejorar la cooperación económica y comercial, asegurar el 
abastecimiento energético, incrementar la presencia de la cultura y la lengua españolas y fomentar la cooperación en la lucha contra el terrorismo y otros temas de la agenda de seguridad (narcotráfico, trata de blancas, tráfico de armas,...).

\subsubsection{Primera etapa: $1991-1996$}

En esta primera etapa, que coincide con los últimos Gobiernos de Felipe González, se establecen relaciones con los países de Asia Central pero sólo se impulsan con Kazajstán y Uzbekistán, además de que todas las gestiones se hacen desde Moscú.

El primero de estos Estados con los que España estrecha relaciones es con Kazajstán por ser un país rico en hidrocarburos. De ahí que el primer acuerdo que se firma es el "Acuerdo para la promoción y protección recíproca de inversiones entre el Reino de España y la República de Kazajstán"46, hecho en Madrid el 23 de marzo de $1994^{47}$.

Dicho Acuerdo fue muy importante pues se ponían todos los mecanismos legales para proteger las inversiones españolas en Kazajstán, como se señaló en el debate parlamentario, pues en caso de "de guerras, motines, conflictos armados y cuestiones similares. En este caso, y como es normal en los convenios internacionales, los acuerdos se refieren a la legislación interna de los países afectados, con lo cual normalmente un país más desarrollado que otro en su propia legislación y, marco jurídico queda realmente desprotegido". Esto se recoge en el art. $6^{48}$.

Otro asunto que cabría destacar de este Acuerdo es la cuestión de las nacionalizaciones y expropiaciones (art. 5). Aunque este tipo de acciones no son exclusivas de los países comunistas (la Constitución Española también contempla esta posibilidad) hubo que hacer un esfuerzo redoblado para vender la imagen fuera de Kazajstán de que su pasado comunista había quedado atrás y que los inversores extranjeros podían estar seguros de que no iban a perder sus negocios de manera arbitraria porque alguna autoridad invocara la "necesidad perentoria del Estado" para hacerse con sus bienes, de manera que se introdujeron una serie de cláusulas que endurecían el recurso a este tipo de medidas y se especificaba que si llegaba a darse el caso "La indemnización será equivalente al valor de mercado de la inversión, inmediatamente antes del momento en que las decisiones de nacionalizar o expropiar hayan sido anunciadas o publicadas" (art. 5.2).

No obstante, no hubo una gran afluencia de inversiones españolas hacia la joven república de Kazajstán, debido a varios factores, que bien se podría resumir en una sola palabra: miedo. La falta de confianza, el temor a que la inversión no vaya a ser todo lo segura que se desearía o todo lo provechosa que se quisiera, frenó que los españoles invirtieran en Kazajstán, aunque no sólo allí. La incertidumbre causada por la caída del bloque comunista fue tal que muy pocos creyeron encontrarse realmente ante el fin, pacífico, de la era soviética

\footnotetext{
${ }^{46}$ Publicado en el BOE n ${ }^{\text {10 }}$ 104/1996, de 30 de Abril de 1996.

${ }^{47}$ Para conocer los preparativos de este acuerdo, ver la intervención de Izquierdo Juárez en la Comisión de Asuntos Exteriores del Congreso de los Diputados: "El compromiso de acuerdo nació durante la visita del Secretario de Estado de Comercio a la República de Kazajstán en mayo de 1993. En julio de ese mismo año se remitió el proyecto de acuerdo a nuestra Embajada en Moscú y el 9 de marzo se negoció el acuerdo, que fue rubricado por ambas partes el día 10. Un año prácticamente después, hoy, 8 de marzo de 1995, lo traemos a las Cortes para su ratificación. Su objetivo, señorías, es fomentar la inversión productiva española en Kazajstán y para ello se ofrece un marco jurídico de protección a las inversiones allí dirigidas. También en la parte expositiva del acuerdo se establece que la inversión extranjera que capte la República de Kazajstán servirá para acelerar el proceso de apertura y desarrollo económico del país”. BOCG, no. 448, de 8 Marzo de 1995, p. 13690.

${ }^{48}$ Ibidem.
} 
y muchos temieron revueltas sociales debido al choque brutal con la economía de mercado, la desprotección social, la desaparición de un sistema de pensiones, etc. Esta medida entró en vigor en marzo de 1995.

Firmado el mismo día 23 de marzo de 1994 pero con entrada en vigor bastante posterior, se llegó a un Acuerdo sobre cooperación económica e industrial entre el Reino de España y la República de Kazajstán ${ }^{49}$.

\subsubsection{Segunda etapa: $1996-2004$}

José María Aznar fue investido Presidente del Gobierno el 4 de mayo de 1996 con el apoyo de CiU, PNV y Coalición Canaria. A partir de ese momento encontramos que se intensifican los contactos al más alto nivel entre España y Kazajstán y Uzbekistán. Así, el presidente Aznar se entrevistó en 1996 con Nazarbayev aprovechando la cumbre de la OSCE en Lisboa ${ }^{50}$. Además, Aznar visitó Almaty, cuando aún era capital de Kazajstán, en $1997^{51}$.

En 1997 también entró en vigor un Acuerdo que ya había sido firmado en 1994 con Kazajstán ${ }^{52}$, al que ya hemos hecho referencia antes. Es este un acuerdo muy general, vago y breve que simplemente anima a la cooperación entre las partes (art. 3), por ejemplo, de tipo económico y empresarial (incluyendo la agricultura, la industria y los servicios), estudiando e identificando "proyectos de interés común en campos como la industria, la construcción, los recursos naturales y la energía". Muy interesante es la "creación, por parte del país receptor, de condiciones favorables para las inversiones de la otra parte y la cooperación para la realización de proyectos de inversión" y las "consultas y cooperación en relación a la protección de los derechos de propiedad industrial, patentes y derechos de autor, en el marco de la legislación existente en ambos países".

En 1998 se firma y entra en vigor un Convenio de Cooperación Cultural, Educativa y Científica entre el Reino de España y la Republica de Kazajstán ${ }^{53}$. Dicho convenio, de tan solo nueve artículos, está orientado, de manera muy general, a facilitar y promover la cooperación cultural entre ambos países. No se contempla ninguna medida concreta, sino que simplemente se ofrecen las mayores facilidades para que se dé esa cooperación entre los Gobiernos pero también entre miembros de la sociedad civil. Nada se dice de la creación ni de un Instituto Cervantes ni de un Aula Cervantes, cosa que el presidente Zapatero prometió para 2012.

La Agenda de esta etapa de la Política Exterior Española tiene un eje vertebrador: la lucha contra el terrorismo. De ahí el acercamiento a EE.UU. y los giros hacia posturas más atlantistas que europeístas, aunque bien es cierto que España cobró peso dentro del Consejo. Muy relacionado con la política pro-estadounidense de la etapa Aznar, está la mayor implicación española en Asia Central, especialmente tras los atentados del 11-S y las operaciones en Afganistán.

\footnotetext{
${ }^{49}$ Publicado en el BOE no 261/1997, de 31 de Octubre de 1997.

${ }^{50}$ Ver el Diario de Sesiones del Congreso de los Diputados, no 130, de 18 de Diciembre de 1996, p. 3574.

51 Ver Skuchalin, Maxim: “Kazakhstan - Spain: to tap the relations' potential”, Kazakhstanskaya Pravda, 18 Octubre 2011, en http://www.kazpravda.kz/c/1308997189.

${ }^{52}$ Es el Acuerdo sobre cooperación económica e industrial entre el Reino de España y la República de Kazajstán, firmado en Madrid el 23 de marzo de 1994. Ver BOE n 261, de 31 de Octubre de 1997.

${ }^{53}$ Se firmó en Alma-Ata el 27 de octubre de 1997 y se publicó en el BOE no 258, de 28 de Octubre de 1998.
} 
Como se verá más adelante, el Plan Asia I del año 2000 supuso un cambio de consideración con respecto a la región, tomada como un todo (Asia entera) y no sólo individualmente (Japón, China, India,...) como se había hecho hasta ese momento lo que puso de manifiesto el interés del Gobierno por tomarse en serio la presencia española allí.

Por último, en esta etapa nos encontramos la entrada en vigor en 2003 del Acuerdo para la promoción y protección recíproca de inversiones entre el Reino de España y la República de Uzbekistán. Muy importante de este acuerdo es la mayor garantía que se da a las inversiones extranjeras de ambas partes, en primer lugar otorgándole el tratamiento de "nación más favorecida" (art. 4) y protegiéndoles frente a expropiaciones y nacionalizaciones arbitrarias (art. 5) y asegurándoles una expropiación a precio de mercado si tal caso llegara a suceder.

Como sello a esta especial relación entre ambos países, el Gobierno de Aznar concedió en 2003 el Collar de la Orden del Mérito Civil a Islam Karimov ${ }^{54}$ y la Gran Cruz de la Orden del Mérito Civil a su mujer, Tatyana Karimova ${ }^{55}$.

Por último, de esta etapa hay que recordar que tras el atentado del 11-S comenzó la campaña en Afganistán, empresa a la que la España de Aznar se sumó, por lo que se estrecharon las relaciones con los países centroasiáticos, solicitando su permiso para sobrevolar su espacio aéreo con material bélico y tropas, además de material de apoyo logístico, y permiso para establecernos en la base de Manas, donde se alojó el destacamento Mizar $^{56}$.

\subsubsection{Tercera etapa: $2004-2011$}

José Luis Rodríguez Zapatero fue investido Presidente del Gobierno el 16 de abril de 2004 con el apoyo de Izquierda Unida, Iniciativa per Catalunya-Verds, Chunta Aragonesista, Esquerra Republicana de Catalunya y Coalición Canaria.

El presidente Zapatero tuvo el acierto de recoger la herencia que le había dejado Aznar con respecto a Asia y, además, quiso dar mayor envergadura a las relaciones con el Lejano Oriente. Esto implicó, en época de bonanza económica, un ambicioso plan de expansión de nuestras relaciones plasmado en el Plan Asia II. A partir de este momento, las relaciones con los países centroasiáticos reciben un mayor impulso y se estrechan aún más con los dos grandes y hay un pequeño acercamiento a las otras tres repúblicas. La línea que había permanecido inalterada desde Felipe González en cuanto a la Política Exterior Española hacia Asia Central era la del pragmatismo, es decir, la defensa de nuestros intereses por encima de todo; sin embargo, dicha norma se rompe y se deja paso a un mayor interés por otros temas más relacionados con los valores o con la ideología y, en esta etapa, el Gobierno lanzó la propuesta de la Alianza de Civilizaciones, asunto sobre el que se tuvieron que pronunciar todos los gobiernos con los que se entró en contacto durante esa primera legislatura. Así, en la ronda de contactos que Moratinos hizo como presidente de turno de la OSCE cosechó un gran apoyo a tal iniciativa.

\footnotetext{
${ }^{54}$ Ver el RD 106/2003, de 27 de enero, publicado en el BOE no. 24 de 28 de Enero, p. 3585.

${ }^{55}$ Ver el RD 128/2003, de 31 de enero, publicado en el BOE no. 44 de 20 de Febrero, p. 7132.

${ }^{56}$ Ver "Visita al contingente español en Afganistán y Kirguistán. Afganistán y Kirguistán, 17 de junio de 2008", Casa Real, 17 de Junio de 2008, en http://www.casareal.es.
} 
Los acontecimientos de Andiján (mayo de 2005) ${ }^{57}$ hicieron que cambiara la relación de Uzbekistán con EE.UU. y con la UE, lo que afectó, también, a la permanencia en suelo kirguiz del destacamento Mizar y el paso por el espacio aéreo del resto de repúblicas ex soviéticas. Finalmente, se llegó a un acuerdo con la OTAN por el que se permitía el paso de material logístico, pero no de soldados ni de material bélico, además de trasladar en octubre de 2009 la base de Manas (Kirguistán) a Dushanbe (Tayikistán), con los inconvenientes que eso trajo consigo.

La actitud de Uzbekistán provocó que Kazajstán se beneficiara y recibiera mayor atención por parte de los socios europeos y americanos, y España no fue una excepción. En los años en que se mantuvo la tensión entre Uzbekistán y Occidente, España firmó al menos tres acuerdos y preparó otros dos, profundizando y concretando así los campos de cooperación en los que ya había echado a andar (ver cuadro supra).

En 2007 España ejerció la presidencia rotatoria de la OSCE, y en la reunión ministerial de Madrid se apoyó la candidatura de Kazajstán como próximo presidente de turno ${ }^{58}$, responsabilidad que ejerció en 2010. La presidencia le dio al ministro Moratinos la oportunidad de visitar las cinco repúblicas ${ }^{59}$ y establecer contactos con todos sus presidentes y ministros de Asuntos Exteriores, impulsando así las relaciones con aquellos países miembros de la OSCE con los que apenas habíamos mantenido contacto:

Durante 2007 España desempeña la Presidencia de la OSCE. Se trata de aprovechar el salto cualitativo para incrementar y consolidar la presencia internacional de España, en especial en zonas donde era limitada, como Asia central, o inexistente, como el Cáucaso, y constituye también una muestra del compromiso con un enfoque multilateral a los problemas de seguridad. ${ }^{60}$

Resulta, quizás por eso, más extraña la falta de interés o, si se quiere, de apoyo suficiente a la presidencia kazaja de la OSCE cuando le tocó su ejercicio práctico, algo que se notó a la hora de organizar la Cumbre de Jefes de Estado y de Gobierno que tuvo lugar los días 1 y 2 de diciembre de 2010 en Astaná. España no pudo o no supo presionar a sus colegas americanos y europeos para que enviaran a representantes del más alto nivel y, de hecho, nuestro Gobierno envió al vicepresidente tercero, Manuel Chaves, cuyas áreas de trabajo poco tienen que ver con el ámbito internacional.

\footnotetext{
${ }^{57}$ Para una explicación más detallada de lo sucedido allí, ver Alonso, Antonio: “Andiján, un año después: Repercusiones en la Política Exterior de Uzbekistán”, UNISCI Discussion Papers, no 11 (Mayo de 2006), en http://www.ucm.es/BUCM/revistas/cps/16962206/articulos/UNIS0606230191A.PDF.

${ }^{58}$ Ver la Declaración del ministro de Asuntos Exteriores y de Cooperación, Miguel Ángel Moratinos Cuyaubé, ante el Consejo Permanente de la OSCE, en Viena, 11 de Enero de 2007. Ver también la Intervención del presidente en ejercicio de la OSCE y ministro de Asuntos Exteriores y de Cooperación, Miguel Ángel Moratinos Cuyaubé, ante el Consejo De Seguridad de las Naciones Unidas, en Nueva York, 28 de septiembre de 2007. Y, por último, la Declaración del presidente en ejercicio de la OSCE y ministro De Asuntos Exteriores y de Cooperación, Miguel Ángel Moratinos Cuyaubé, en la sesión de clausura del décimo quinto Consejo Ministerial de la organización, en Madrid, 30 de Noviembre de 2007.

${ }^{59}$ El ministro de Asuntos Exteriores y de Cooperación, Miguel Ángel Moratinos, partió rumbo a Kazajstán, primera escala de su gira por Asia Central, que le llevó a Turkmenistán, Uzbekistán, Kirguizistán y Tayikistán el 9 de abril de 2007

${ }^{60}$ Ver la "Comparecencia del ministro de Asuntos Exteriores y de Cooperación, Miguel Ángel Moratinos Cuyaubé, ante la Comisión de Asuntos Exteriores del Congreso, para informar sobre el balance de la Política Exterior Española”, Diario de Sesiones del Congreso de los Diputados nº 856, de 19 de Junio de 2007, p. 6.
} 
Fruto de la presidencia española de la OSCE es la creación de una Oficina Consular Honoraria en Bishkek (Kirguistán) en 2007. En la motivación de dicha creación se expone que

Asia Central es una región de importancia estratégica creciente, en la que España desea reforzar su presencia. La creación de una Oficina Consular Honoraria en Bishkek ayudaría a estrechar los lazos entre Kirguistán y España en todos los ámbitos: político, económico, turístico y comercial y aunque la colonia española residente en Kirguistán es reducida, son numerosos los turistas españoles que visitan el país. ${ }^{61}$

Del año 2010 cabe destacar la firma del Acuerdo de Asociación Estratégica entre el Reino de España y la República de Kazajstán ${ }^{62}$, que implica una subida de nivel en las relaciones entre Estados y que facilitará en un futuro no muy lejano una mayor presencia española en el país estepario, no sólo con empresas sino con intercambios culturales y educativos. Además, se recuerda que un condicionante de las relaciones entre España y Kazajstán es el respeto a los Derechos Humanos y la democracia (art. 4) y se subraya la cooperación en materia de seguridad (art. 5):

De conformidad con sus obligaciones internacionales y sus legislaciones nacionales, las Partes cooperarán, tanto en sus relaciones multilaterales como bilaterales, en los ámbitos de la lucha contra las amenazas y desafíos a la seguridad, de la no proliferación de armas de destrucción masiva y del apoyo al desarrollo sostenible. Las Partes desarrollarán su actividad conjunta y su cooperación, tanto en sus relaciones multilaterales como bilaterales, en el ámbito de la lucha contra el terrorismo, la delincuencia organizada transnacional, el tráfico ilegal de estupefacientes y sus precursores, así como contra el comercio ilegal de armas y otros tipos de delitos en los territorios del Reino de España y de la República de Kazajstán.

Si Kazajstán abrió en 1999 su embajada en España, Uzbekistán no lo hizo hasta 2007. Las diferencias entre ambos países en cuanto a su representación ante el reino de España se vieron ligeramente salvadas con la designación en $2009^{63}$ de Gulnara Karimova, hija del presidente uzbeko Karimov, como embajadora ${ }^{64}$. Además, la embajada uzbeka en Madrid está llevando a cabo una serie de actividades con el mundo empresarial que se están traduciendo en inversiones en su país, aunque sin llegar, claro está al nivel de Kazajstán.

El Gobierno de Zapatero tuvo que responder a la turbulenta situación de Kirguistán en dos ocasiones (2005 y 2010), aunque también lo hizo a través de la UE, como se ha visto

\footnotetext{
${ }^{61}$ Ver la ORDEN AEC/3137/2007, de 22 de Octubre, publicada en el BOE no 261, de 31 de Octubre de 2007, p. 970 .

${ }^{62}$ Ver BOE no 234, de 27 de Septiembre de 2010, pp. 81627-31.

${ }^{63}$ Presentó las copias de las cartas credenciales al Rey el 18 de enero de 2010. Ver "Uzbekistan: President's daughter Gulnara Karimova to become the Ambassador in Spain”, Ferghana.News, 22 de Enero de 2010, en http://enews.fergananews.com.

${ }^{64}$ Gulnara Karimova finalñizó su mandato en España en septiembre de 2011, pasando a ser embajadora ante el Reino Unido, debido a motivos familiares (para estar más cerca de sus hijos, a quienes había enviado allí a estudiar). Le ha sustituido al frente de la embajada Dilshod Ahatov, embajador de Uzbekistán en Berlín desde mayo de 2010. La embajada uzbeka en Alemania es la más importante que este país posee en Europa. Con este acontecimiento, la balanza vuelve a desequilibrarse a favor de Kazajstán. Sin embargo, eso no obsta para que el presidente Karimov haya felicitado a D. Juan Carlos I por la celebración de la Fiesta Nacional del 12 de octubre. Ver "Greetings to the King of Spain", Ministerio uzbeko de Asuntos Exteriores, 8 de Octubre de 2011, en http://mfa.uz/eng.
} 
anteriormente. Cuando ejerció su presidencia de turno el primer semestre de 2010 tuvo que emitir un comunicado, pero lo hizo desde la Dirección General de Comunicación Exterior del $\mathrm{MAEC}^{65}$, no sólo desde los órganos de la UE. En dichos comunicados hace un llamamiento a la resolución pacífica de la situación y elogia el papel de la presidencia kazaja de la OSCE en la negociación de la salida del presidente Bakiyev del país, evitando así un mayor derramamiento de sangre.

El colofón a esta etapa lo ofreció la visita del presidente Zapatero a Kazajstán los días 16 y 17 de junio de 2011, donde, de camino al Foro Económico Internacional en San Petersburgo, acompañado de una amplia comitiva de empresarios (Repsol, Indra, Talgo, CAF, Abengoa, Airbus o Técnicas Reunidas, entre otras) que llegaron a firmar acuerdos con la contraparte kazaja. Aquí se puede ver el giro hacia una diplomacia más económica que ideológica. Zapatero, además se entrevistó con Nazarbayev y con el Primer Ministro Masimov, a quienes expresó su deseo de profundizar en las buenas relaciones ya existentes entre ambos países ${ }^{66}$.

Otro éxito que podríamos incluir en esta etapa es la inauguración de la línea Taskent Samarcanda, cuyo primer viaje fue el 26 de agosto de 2011, y que supuso la culminación de la cooperación entre ambos países y entre la empresa española Talgo y las empresas uzbekas ${ }^{67}$.

\section{Asia Central en el organigrama del MAEC}

En su Discurso de investidura, de 8 de abril de 2008, el Presidente Zapatero hizo un repaso somero, como no podría ser de otra forma, de las principales líneas de acción de nuestra Política Exterior. Por orden de cita, aparece nuestra vocación europeísta, Iberoamérica, EE.UU., el Mediterráneo, el Plan África y el cumplimiento de los compromisos con la ONU (especialmente los Objetivos del Milenio). Nada, en absoluto, de Asia y menos de Asia Central.

Los asuntos de esta región se tratan, actualmente, en la Subdirección General de Europa Oriental y otros Países Europeos no Comunitarios, dependiente de la Dirección General de Política Exterior para Europa No Comunitaria y América del Norte, integrada en la Secretaría de Estado de Asuntos Exteriores. El motivo que se aduce para esto es que así es como lo hacen el resto de Ministerios de Asuntos Exteriores europeos. Sin embargo, la Secretaría de Estado norteamericana desgajó los asuntos de Asia central del espacio postsoviético y los unió a los de Asia Meridional (Afganistán y Pakistán) con la intención de darle un nuevo marco a Afganistán e impulsar la estabilización de la zona.

Sin embargo, incluir a Asia Central en la sección de Europa Oriental no tiene mucho sentido puesto que no es un país europeo, sino mas bien asiático, por lo que debería existir una Dirección General dedicada a Asia, no englobada en la actual "para América del

\footnotetext{
${ }^{65}$ Ver el Comunicado de Prensa 29-2010 “Situación en Kirguistán”, 8 de Abril de 2010, en http://www.maec.es. Ver también el Comunicado de Prensa 35-2010 "Situación en Kirguistán”, 19 de Abril de 2010, en http://www.maec.es.

${ }^{66}$ La inversión total de España en Kazajistán se estima en 115,2 millones US\$, mientras que el volumen total de comercio bilateral ascendió a 1,021 billones US\$. Ver Delaney, Greg: "Kazakh Hispano Economic Cooperation to Expand", Kazakhstanlive.com, 21 de Junio de 2010, en http://www.kazakhstanlive.com.

${ }^{67}$ Ver Bonet, Pilar: "Uzbekistán ningunea a España en la puesta en marcha del AVE", El País, 30 de Agosto de 2011, en http://www.elpais.com.
} 
Norte, Asia y Pacífico”. Además, eso sería más coherente con la inclusión de Asia Central en los sucesivos Plan Asia.

Aunque exista un embajador en misión especial para Asia Central ${ }^{68}$, la ubicación dentro del organigrama ministerial revela que se trata de un asunto poco importante, muy por detrás de los grandes asuntos de interés para la Política Exterior Española como son Europa, el Mediterráneo, Iberoamérica y el vínculo trasatlántico. Tanto Asia Pacífico, como Asia Central o incluso África Subsahariana, han atraído poco su atención tradicionalmente.

Si antes de 2008 había perspectivas de que se le podía dar un fuerte impulso a este apartado dentro del Ministerio y dentro del diseño de la Política Exterior por parte del Gobierno, la crisis económica y financiera mundial impuso un freno a la innovación, traducido en un recorte del gasto presupuestario. Aunque se esperaban reformas, cerrando algunos consulados en Europa poco útiles ya, que permitieran la apertura de una embajada en Uzbekistán, dichas reformas no llegaron; en parte por la crisis económica, en parte por la precaria situación política interna que ha debilitado el sistema institucional, con un Gobierno que se desprestigia a sí mismo anunciando cada mes el final de la crisis, con una oposición centrada en adelantar las elecciones generales, y con una población que en lugar de exigir ese adelanto de elecciones innovó saliendo a las calles para participar en la vida pública de manera diferente a como se venía haciendo en España (sólo en las urnas, eventualmente recurriendo a manifestaciones puntuales). La crisis económica ha traído una crisis institucional donde el establishment está desprestigiado desde dentro y desde fuera, por parte de la propia clase política y por una porción de la ciudadanía muy descontenta, indignada, con los abusos del sistema político y económico español.

No obstante, el Ministerio de Asuntos Exteriores sigue haciendo una serie de gastos difíciles de justificar, especialmente en época de crisis, desviando fondos a proyectos que poco tienen que ver, a primera vista, con la Política Exterior ${ }^{69}$ en vez de dirigirlos a gastos más racionales, como podría ser el impulso de las relaciones políticas y comerciales con Asia, centro del desarrollo de este siglo XXI, como queda expuesto en todos los Plan Asia.

En lo que se refiere a nuestra representación diplomática en la región, conviene repasar el BOE y hacer un par de aclaraciones. En primer lugar, se puede observar que, como es lógico, en un primer momento (1992) quien ostentaba la representación de España ante la Unión Soviética, la ostentará ante la nueva Rusia y los nuevos países nacidos de la caída de la $\mathrm{URSS}^{70}$. De esta manera, el puesto en Moscú implicaba la acreditación múltiple ante las naciones de Asia Central, lo que explica qué consideración tenían a comienzo de los años 90:

\footnotetext{
${ }^{68}$ Este puesto lo han ocupado sucesivamente Santiago Chamorro y Fernando de la Serna Inciarte. Ver en el BOE no 39 de 14/2/2009, p. 15622, el RD 171/2009, de 13 de febrero, por el que se designa Embajador en Misión Especial para Asia Central a don Santiago Chamorro y González-Tablas, y ver también en el BOE nº 227 de 18/9/2010, p. 79379 el Real Decreto 1182/2010, de 17 de septiembre, por el que se designa Embajador en Misión Especial para Asia Central a don Fernando de la Serna Inciarte.

${ }^{69}$ Algunos ejemplos: un bus pro-aborto en Bolivia, asistencia a los gays y lesbianas de Tanzania o fuertes subvenciones a la Fundación Ideas (vinculada al PSOE). Ver el BOE nº 195 del jueves 13 de agosto de 2009, pp.68859ss. Ver también "Sigue el despilfarro en Exteriores: 82 millones en subvenciones en tres meses", Libertad Digital, 12 de Agosto de 2011, en http://www.libertaddigital.com. Ver también "Exteriores subvenciona con 9000 euros el respeto a las transexuales en el Caribe: Asociaciones homosexuales reciben otros 26.000 euros", La Razón, 18 de Agosto de 2011, en http://www.larazon.es.

${ }^{70}$ Eugeni Bregolat Obiols fue designado embajador ante la Federación Rusa por RD 130/1992, de 14 de febrero (ver BOE n. 42/1992, de 18 de febrero, pp. 5587s). Después, fue designado embajador en Turkmenistán por RD 485/1992, de 8 de mayo; en Uzbekistán por RD 486/1992, de 8 de mayo (ver BOE n. 115/1992, de 13 de mayo, p. 16161); en Kirguistán por RD 611/1992, de 5 de junio (ver BOE n. 138/1992, de 9 de junio, p. 19334); y finalmente en Kazajistán por RD 1224/1992, de 9 de octubre (ver BOE n. 245/1992, de 12 de octubre, p. 34519).
} 
un simple apéndice de Rusia. No obstante, poco a poco, España va tomando conciencia, por un lado, de la importancia, del potencial que le ofrecen a nuestro país aquellas tierras y, por otro lado, de que los nuevos países desean reafirmar su independencia marcando cierta distancia con la Federación Rusa. Hay que tener en cuenta, además, que la embajada en Rusia es un destino de primera categoría junto a las embajadas ante EE.UU. y la Santa Sede, por lo que en ocasiones ha sido utilizada como premio a los servicios prestados (obviamente, en otras ocasiones se ha puesto al frente de Moscú a diplomáticos de carrera muy competentes para resolver situaciones delicadas).

Es en 1999 cuando la representación de Kazajstán (a la que irán aparejadas Kirguistán y Tayikistán) $^{71}$ se desgaja de la de Moscú. Sin embargo, Rusia y Uzbekistán (junto a la de Turkmenistán) irán, hasta la fecha, juntas. Esta es una muestra de cómo las cancillerías europeas entienden que no pueden mantener a la misma persona al frente de las legaciones en Kazajstán y Uzbekistán por incompatibilidad de intereses, pero sí en Uzbekistán y Rusia. No obstante, esta especie de "agravio comparativo" no podrá mantenerse por mucho tiempo y más temprano que tarde (cuando pasen los efectos de la presente crisis económica o se incremente considerablemente el volumen de negocio con aquel país) se creará una misión diplomática permanente propia en Uzbekistán separada de la de Moscú. No parece de recibo haber tenido acreditada en España como embajadora a Gulnara Karimova, hija del Presidente de la República de Uzbekistán, y no tener ni siquiera un embajador propio allí.

\begin{tabular}{|c|c|c|c|}
\hline & Rusia & Uzbekistán & Kazajstán \\
\hline 1987 & \multicolumn{3}{|c|}{ José Cuenca Anaya } \\
\hline 1992 & \multicolumn{3}{|c|}{ Eugeni Bregolat Obiols } \\
\hline 1996 & \multicolumn{3}{|c|}{ José Antonio de Yturriaga Barberán } \\
\hline 1999 & \multicolumn{2}{|c|}{ José Luis Crespo de Vega } & \multirow{3}{*}{$\begin{array}{c}\text { Francisco Pascual de } \\
\text { la Parte }\end{array}$} \\
\hline 2001 & José & Fraga & \\
\hline 2004 & \multirow{2}{*}{\multicolumn{2}{|c|}{ Francisco Javier Elorza Cavengt }} & \\
\hline 2005 & & & \multirow{2}{*}{$\begin{array}{c}\text { Santiago Chamorro y } \\
\text { González-Tablas }\end{array}$} \\
\hline 2007 & \multirow{2}{*}{\multicolumn{2}{|c|}{ Juan Antonio March Pujol }} & \\
\hline 2008 & & & \multirow{2}{*}{ Alberto Antón Cortés } \\
\hline 2011 & \multicolumn{2}{|c|}{ Luis Felipe Fernández de la Peña ${ }^{72}$} & \\
\hline
\end{tabular}

\footnotetext{
${ }^{71}$ Por RD 2536/1998, de 27 de noviembre, se crea la Misión Diplomática Permanente de España en la República de Kazajstán (ver BOE número 297 de 12/12/1998, p. 41379). Por RD 709/1999, de 30 de abril, se designa a Francisco Pascual de la Parte Embajador de España en la República de Kazajstán (ver BOE número 104 de 1/5/1999, p. 16118).

72 A fecha 30 de agosto, el embajador Fernández de la Peña asistió a la inauguración del primer tren de alta velocidad en Asia Central construido por Talgo en Uzbekistán, que unirá las ciudades de Taskent y Samarcanda, sin haber recibido aún el placet para ser embajador ante Uzbekistán. Ver Bonet, op. cit.. Su nombramiento ha
} 
Algo que también se deduce de este cambio de estructura de las misiones diplomáticas de España en el exterior es que las relaciones con Kazajstán recibieron un fuerte impulso con José María Aznar debido a que por ambas partes existía (y aún hoy existe) un gran interés por profundizar en dichas relaciones. Para entrar más en detalle, no es comparable la estabilidad ${ }^{73}$ que se le ha dado a la misión diplomática en Astaná con la de Moscú-Taskent, ya que el promedio para la primera es de 4-5 años mientras que para la segunda es de 2-3 años.

\section{Asia Central en los "Plan Asia"}

Además de los acuerdos firmados con algunos Estados de Asia Central, los sucesivos Gobiernos de España han diseñado desde el año 2000 una estrategia, una reflexión en torno a cuestiones básicas de un Política Exterior que se precie (qué objetivos se persiguen, qué intereses hay que proteger, qué se quiere hacer, dónde, cómo, por qué, con qué dinero se cuenta para ello), una propuesta que se torna posteriormente en acción de gobierno, en ejecución del diseño planteado y que, posteriormente, debe ser evaluada. Los distintos Plan Asia responden a estas preguntas con datos concretos, además de las habituales consideraciones de carácter general.

Decía Henry Kissinger que el eje geopolítico oscilaría del Atlántico al Pacífico ${ }^{74}$ y, a la vista de los datos, razón no le falta. Como recoge el Plan Asia I (2000-2004), la región de Asia Pacífico alberga a cerca de la mitad de la población mundial y acumula un alto porcentaje del PIB mundial. Además, sus sociedades, en plena expansión económica, serán el motor del consumo para este siglo XXI. Sus fuentes de energía (principalmente gas, petróleo, uranio) hacen de esta región un objeto codiciado por los países desarrollados y también por los que están desarrollándose y necesitan de manera sobreabundante de esos recursos naturales. El Gobierno de Aznar, en su segunda legislatura, diseñó una acción de gobierno que se centrara, por primera vez en la Historia de España, en la región descrita anteriormente.

Sin embargo, en este Plan Asia $I^{75}$ no aparece Asia Central como objeto de la Política Exterior. Esto se debe a que todavía no se había puesto en práctica ninguna acción de gobierno ordenada hacia aquella región y se vio en seguida que era un error dejar fuera de este plan a una de las regiones del planeta más ricas en hidrocarburos y que seguía una lógica más parecida a la del resto de Asia que a la del resto de Europa Oriental.

En el Plan Asia II (2004-2008) se afirma que se estudiaría

la creación, en el Ministerio de Asuntos Exteriores y de Cooperación, de una subdirección general de Asia Central y Meridional que dé coherencia al seguimiento de lo que acontece en

\footnotetext{
despertado polémica entre los diplomáticos españoles, ver "El Gobierno cambió a la mitad de los embajadores en el último año", $A B C, 12$ de Septiembre de 2011, en http://www.abc.es.

${ }^{73}$ Las Relaciones Internacionales en general y la Política Exterior en particular se basan en la confianza mutua, más bien en saber de quién te puedes fiar y de quién no puedes hacerlo. Precisamente, mantener a la misma persona al frente de una legación implica que, si hace bien su trabajo, tiene tiempo suficiente para trabar un entramado de relaciones personales que faciliten las relaciones institucionales, esto es, las relaciones de Estado a Estado. Obviamente, si una persona permanece en el cargo un año o dos apenas habrá tenido tiempo para empezar su labor.

74 "In our age, the rise of China as a potential superpower is of even greater historical significance, marking as it does a shift in the center of gravity of world affairs from the Atlantic to the Pacific". Ver Kissinger, Henry A.:

“America's Assignment: What will we face in the next four years?", Newsweek, 8 de Noviembre de 2004.

${ }^{75}$ Su nombre oficial es Plan Marco Asia Pacífico 2000-2002.
} 
esa región y en Irán, como consecuencia de nuevos escenarios geoestratégicos en el continente, que actualmente se trata desde tres direcciones generales distintas en el MAEC. ${ }^{76}$

Efectivamente, esto habría sido una buena noticia si se hubiera llegado a producir, pero lamentablemente tal subdirección general jamás llegó a crearse, aunque sí se creó una más general referida a Asia continental, pero dentro de la Dirección General de Política Exterior para Asia y Pacífico ${ }^{77}$.

Las referencias a Asia Central quedan reducidas en el Plan Asia III (2008-2012) al seguimiento del cumplimiento de los compromisos en materia de Derechos Humanos adquiridos por los países centroasiáticos con la UE en su Estrategia de 2007 y sus respectivos diálogos $^{78}$. No obstante, en la presentación del Plan Asia III en la Comisión de Asuntos Exteriores del Senado por parte del Secretario de Estado de Asuntos Exteriores, Ángel Lossada Torres-Quevedo, hizo hincapié en que nuestro interés en la zona no se limita sólo a la promoción de los Derechos Humanos sino que buscamos allí garantizar la estabilidad y seguridad de la zona, conscientes de que es esencial para la estabilidad de Europa:

Otro elemento que también ha sido subrayado por todos $-\mathrm{y}$ considero de gran importancia que se produzca esta coincidencia- es la preocupación por los temas sobre seguridad junto a los grandes temas económicos; seguridad en relación con los equilibrios más tradicionales de fuerzas y la forma de abordarlos, así como en relación con las amenazas emergentes u otras situaciones más estructurales: terrorismo, criminalidad organizada y trata de seres humanos, sin olvidar el elemento destacado de la seguridad en Asia central, la cuestión de Afganistán, tan importante, y las cuestiones relativas a la proliferación derivadas de la situación en la India, Pakistán o Corea. ${ }^{79}$

Así queda reflejado también en el Panorama estratégico 2011-2012 elaborado por el Ministerio de Defensa: "Limitar el conflicto y su solución a Afganistán y Pakistán es una estrategia restrictiva. Sin salirnos de la región, son actores externos del nuevo juego Pakistán, Irán, India, Rusia, las repúblicas centroasiáticas, China e incluso Arabia Saudita". ${ }^{0}$

En definitiva, podemos esperar que el próximo Plan Asia IV, que seguro llegará, tomará más en serio la región de Asia Central, siguiendo la tendencia iniciada por Aznar y continuada por Zapatero, ya que estar presentes en Asia no es una opción sino prácticamente una "obligación", y Asia Central se ha convertido en los últimos años en punto de referencia para garantizar el suministro energético.

\footnotetext{
${ }_{76}^{76}$ Plan Asia II, p. 44.

77 Ver Real Decreto 1124/2008, de 4 de julio, por el que se desarrolla la estructura orgánica básica del Ministerio de Asuntos Exteriores y de Cooperación, art. 7, p. 10.

${ }^{78}$ Plan Asia III, p. 90.

${ }^{79}$ Ver la "Comparecencia del Secretario de Estado De Asuntos Exteriores, Ángel Lossada Torres-Quevedo, ante la Comisión de Asuntos Exteriores del Senado, para presentar la Política Exterior Española hacia Asia: El Plan Asia Pacífico 3", Diario de Sesiones del Senado, no. 107, de 19 de Febrero de 2009, p. 15.

${ }^{80}$ Ver Enseñat y Berea, Amador: “Afganistán: el momento de la verdad”, en Real Instituto Elcano: Panorama estratégico 2011-2012, pp. 176-77 y p. 180. Ver también Bustelo, Pablo: “Asia Central: Importancia estratégica y relaciones internas", Análisis del Real Instituto Elcano 85/2010 (19 de mayo de 2010).
} 


\section{Conclusiones}

De todo lo dicho hasta ahora se desprenden una serie de ideas que nos permitirán comprender mejor la situación en Asia Central y nuestra Política Exterior hacia aquella zona:

1.- Los Estados de Asia Central se independizaron hace 20 años de la Unión Soviética. No obstante, es Rusia quien mantiene la mayor influencia (política, económica y cultural) en la región, a pesar de los intentos de otros Estados de penetrar en la región.

2.- Durante estos 20 años, las nuevas naciones han tenido que forjar un nuevo sistema de alianzas estratégicas y, algunas de ellas, han buscado romper su aislamiento iniciando relaciones con países distintos a los ya tradicionales (Rusia, China, Turquía, Irán) diversificando sus relaciones exteriores (EE.UU., Japón, Alemania, Francia, Reino Unido, Corea del Sur, India).

3.- Las relaciones de España con los nuevos Estados de Asia Central se remontan a los primeros momentos de la desintegración de la URSS, aunque fue con José María Aznar cuando recibieron el primer impulso serio y se han consolidado durante las legislaturas de Zapatero. A pesar de los esfuerzos realizados por parte de las administraciones españolas, Asia Central sigue siendo una gran desconocida.

4.- Dichas relaciones siguen dos vías paralelas: la estatal (incluimos aquí también el autonómico y el local) y la comunitario (a través de la UE), lo que hace que se dupliquen esfuerzos y se sea menos eficaz y menos eficiente.

5.- Sin lugar a dudas, nuestros socios prioritarios allí son, por orden de importancia, Kazajstán y Uzbekistán, a quien le siguen Turkmenistán, Kirguistán y Tayikistán. Nuestros intereses en la región son principalmente "energía, infraestructuras y seguridad".

6.- Nuestras relaciones diplomáticas, especialmente en el caso de Kazajstán y de Uzbekistán, gozan de una excelente salud debida, en gran medida, a las buenas relaciones personales existentes entre los respectivos Jefes de Estado, quienes transmitieron a sendos Gobiernos su deseo de que se impulsaran las relaciones políticas (incluidas las de Defensa) y comerciales.

7.- El futuro de la presencia española en Asia Central depende de las facilidades y garantías que se le ofrezcan a las empresas españolas para instalarse allí, para que realicen inversiones en aquella región.

8.- La apertura de un Instituto Cervantes o de un Aula Cervantes supondría un gran avance en la implantación y difusión del español en las naciones centroasiáticas, apoyando la labor que ya realizan lectores españoles en algunas universidades, como por ejemplo la Facultad de Lengua Española o en la Universidad de la Economía Mundial y la Diplomacia, ambas en Taskent.

9.- Aunque ya existen convenios de colaboración entre universidades (especialmente activa en este campo es la de Santiago de Compostela), deberían impulsarse más intercambios de profesores, alumnos e investigadores aprovechando para ello los fondos europeos disponibles para tal fin. También deberían incentivarse los cluster de grupos de investigación, pudiendo ser financiados también por la UE. 
10.- El impulso del turismo entre ambas partes ayudaría a revitalizar las relaciones económicas y comerciales en ambos lados. 